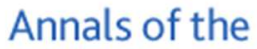 \\ RHEUMATIC DISEASES \\ The Eular Journal
}

\section{Development of a Glucocorticoid Toxicity Index (GTI) Using Multi-Criteria Decision Analysis}

\begin{tabular}{|c|c|}
\hline Journal: & Annals of the Rheumatic Diseases \\
\hline Manuscript ID & Draft \\
\hline Article Type: & Concise report \\
\hline Date Submitted by the Author: & $\mathrm{n} / \mathrm{a}$ \\
\hline Complete List of Authors: & $\begin{array}{l}\text { Miloslavsky, Eli; Massachusetts General Hospital, Rheumatology, Allergy } \\
\text { and Immunology Division } \\
\text { Naden, Ray; McMaster University Faculty of Health Sciences, Maternal- } \\
\text { Fetal Medicine } \\
\text { Bijlsma, Hans; UMCUtrecht, Rheumatology } \\
\text { Brogan, Paul; University College London, Institute of Child Health } \\
\text { Brown, Sherwood; University of Texas Southwestern Medical Center at } \\
\text { Dallas, Psychiatry } \\
\text { Brunetta, Paul; Genentech, Inc., Late Stage Immunology Product } \\
\text { Development } \\
\text { Buttgereit, Frank; Dept of Rheumatology and Immunology } \\
\text { Choi, Hyon; Harvard Medical School, Rheumatology } \\
\text { Dicaire, Jean-Francois; Pinnacle, Inc. } \\
\text { Gelfand, Jeffrey; University of California-San Francisco } \\
\text { Heaney, Liam; Queen's University of Belfast } \\
\text { Lightstone, Liz; Imperial College London, Section of Renal Medicine and } \\
\text { Vascular Inflammation, Division of Immunology and Inflammation } \\
\text { Lu, Na; Massachusetts General Hospital, Rheumatology } \\
\text { Murrell, Dedee; University of New South Wales } \\
\text { Petri, Michelle; Johns Hopkins University, Rheumatology } \\
\text { Rosenbaum, James; Casey Eye Institute, Oregon Health and Science } \\
\text { University, } \\
\text { Saag, Kenneth G; University of Alabama at Birmingham } \\
\text { Urowitz, Murray; University of Toronto, Lupus Clinic, Center for Prognosis } \\
\text { Studies in the Rheumatic Diseases, Toronto Western Hospital } \\
\text { Winthrop, Kevin; Oregon Health Sciences University, } \\
\text { Stone, John; Harvard Medical School, Massachusetts General Hospital } \\
\text { Rheumatology Unit }\end{array}$ \\
\hline Keywords: & Corticosteroids, Outcomes research, Treatment \\
\hline
\end{tabular}

\section{SCHOLARONE \\ Manuscripts}




\title{
Development of a Glucocorticoid Toxicity Index (GTI) Using Multi-Criteria Decision Analysis
}

\author{
Eli M. Miloslavsky, Ray P. Naden, Johannes W. J. Bijlsma, Paul A. Brogan, E. Sherwood \\ Brown, Paul Brunetta, Frank Buttgereit, Hyon K. Choi, Jean-Francois DiCaire, Jeffrey M. \\ Gelfand, Liam G. Heaney, Liz Lightstone, Na Lu, Dedee F. Murrell, Michelle Petri, James \\ T. Rosenbaum, Kenneth S. Saag, Murray B. Urowitz, Kevin L. Winthrop, and John H. \\ Stone
}

Word count: 1,577

This study was funded by an investigator-initiated grant from Genentech.

Please direct correspondence to:

Dr. John H. Stone

Rheumatology Clinic, Yawkey 2

Massachusetts General Hospital

55 Fruit Street

Boston, MA. 02114

Email: jhstone@mgh.harvard.edu 


\begin{abstract}
:
Objectives:

To develop a Glucocorticoid Toxicity Index (GTI) to assess glucocorticoid (GC)-related morbidity and the GC-sparing ability of other therapies.
\end{abstract}

\title{
Methods:
}

Nineteen experts on glucocorticoid use and outcome measures from 11 subspecialties participated. Ten experts were from the United States; 9 from Canada, Europe, or Australia. Group consensus methods and multi-criteria decision analysis (MCDA) were utilized.

\begin{abstract}
A Composite GTI and Specific List comprise the overall GTI. The Composite GTI reflects toxicity likely to change during a clinical trial. The Composite GTI toxicities occur commonly, vary with GC exposure, and are weighted and scored. Relative weights for items in the Composite GTI were derived by group consensus and MCDA. The Specific List is designed to capture GC toxicity not included in the Composite GTI. The Composite GTI was evaluated by application to paper cases by the investigators and an external group of 17 subspecialists.
\end{abstract}

\author{
Results: \\ Thirty-one toxicity items were included in the Composite GTI and 23 in the Specific List. \\ Composite GTI evaluation showed high inter-rater agreement (investigators kappa 0.88, external \\ raters kappa 0.90). To assess the degree to which the Composite GTI corresponds to expert \\ clinical judgment, participants ranked 15 cases by clinical judgment in order of highest to lowest \\ GC toxicity. Expert rankings were then compared to case ranking by the Composite GTI,
}


yielding excellent agreement (investigators weighted kappa 0.87, external raters weighted kappa $0.77)$.

\section{Conclusions:}

We describe the development and initial evaluation of a comprehensive instrument for the assessment of glucocorticoid toxicity. 


\section{INTRODUCTION}

Glucocorticoids (GCs) have been a cornerstone of treatment for many diseases since their introduction more than sixty-five years ago. GC use is associated with considerable treatment morbidity. ${ }^{1,2}$ Although the use of these medications is generally reviled by patients and physicians alike, data on the true incidence of GC-associated adverse events remain scarce because until now GC toxicity has simply been a fact of life for patients with immune-mediated diseases. ${ }^{3}$ The development of novel immunomodulatory agents offers the potential to reduce GC use and to diminish their adverse effects. ${ }^{4,5}$ In order to assess the true benefit of new medications with regard to their steroid-sparing properties, investigators must be able to assess their ability to prevent or reverse GC-related adverse events. Unfortunately, no reliable instrument designed to measure GC-related toxicity both broadly and accurately has been developed.

Measuring GC-related toxicity poses significant challenges. ${ }^{1,6}$ Previous studies examining GCrelated toxicity have utilized different combinations of adverse events with varied event definitions. $^{7,8,9}$ We aimed to develop a GC Toxicity Index (GTI) useful across medical disciplines to assess the impact of GC-associated morbidity.

\section{METHODS}

\section{Participants and procedures}

Twenty-two experts in glucocorticoid use and outcome measures were invited and 19 agreed to serve on the Scientific Committee (SC). Experts represented multiple specialties (rheumatology [including osteoporosis], pediatric rheumatology, pulmonology, nephrology, neurology, 
ophthalmology, dermatology, infectious disease, and psychiatry) and had extensive experience in the clinical use and pharmacology of GCs. Ten investigators were from the United States, nine from Canada, Europe, or Australia.

The development process, which included ten milestones (Figure 1), was conducted over ten one-hour conference calls, work between the calls, and one day-long, face-to-face meeting.

\section{Instrument characteristics and item inclusion criteria}

The SC agreed that the optimal use of the GTI would be in prospective, randomized, controlled clinical trials utilizing GCs, regardless of whether GC therapy is prescribed according to protocol or investigators' best medical judgement. Randomization and blinding serve the critical purposes of controlling for the background rate of adverse events ${ }^{10}$ and prior GC treatment, and also limit the need for attribution.

The SC determined that the GTI would have two components: the Composite GTI and a Specific List. The Composite GTI serves as the primary instrument and is intended to capture common toxicities that are sensitive to differing cumulative GC doses over the period of a typical clinical trial (6 months to 3 years). It is weighted and measures both worsening and improvement. The complementary Specific List captures important GC-related adverse events not included in the Composite GTI. The SC agreed to not weigh Specific List toxicities due to the possible skewing that rare but serious events would introduce into the weighting scheme. 
Item selection for the Composite GTI was based on the following principles: 1) likelihood of occurrence $>5 \%$ in patients exposed to GCs; 2 ) item independence; 3 ) item equivalence (several GC toxicities could be included within a single item, provided they were within the same clinical domain and were equivalent in their degree of toxicity); 4) toxicity is more likely to be due to the effect of GC therapy than the disease itself; 5) toxicity is unlikely to be the result of GC therapy prior to trial entry (e.g., osteoporotic fracture); 6) measurement does not typically require invasive procedures or imaging.

Toxicities that did not meet these criteria but were deemed important and were not confounded by underlying disease or co-morbidities were included in the Specific List. Candidate toxicities were generated based on literature review (Appendix I) and selected for inclusion by nominal group technique. Definitions for each item, developed by experts from the relevant clinical area, were revised by consensus. Items were grouped by clinical domains in order of increasing toxicity such that only one item within each domain could be assigned to a given patient. The draft GTI was reviewed by the SC for clarity, format, visual design, organization, and navigability. Relative weights were then derived at the face-to-face meeting using multi-criteria decision analysis (MCDA) via the 1000Minds software platform (Dunedin, New Zealand)

(Appendix II). ${ }^{11,12}$

\section{Instrument scoring}

The SC agreed that the Composite GTI should measure change in GC toxicity rather than absolute GC toxicity in order to account for the effects of prior GC therapy and background rate of adverse events. Therefore, evaluation at two time points is required for scoring. All domains 
have the potential for improvement (e.g., myopathy can improve from "mild" to "none", even though a specific improvement item is not included in the Composite GTI). When a Specific List item occurs (e.g., death from infection), the most severe corresponding item in the Composite GTI (i.e., Grade 3 infection) is also scored. The Composite GTI should be scored at 3-month intervals throughout the study, using entry assessment as the baseline. Because the bone domain should generally not be scored more often than every 12 months, it should be excluded for trials shorter than 1 year in duration. The score should be reported as both a total score and domain-specific scores, to account for scenarios when improvements in certain domains compensate for worsening in others.

\title{
Evaluation process
}

The performance of the Composite GTI was evaluated by both participating experts and an external, multi-specialty group of 17 testers (Supplementary Table 1) using paper cases. Each expert submitted four patient cases describing GC toxicity. Fifteen cases were chosen to represent the full range of GC toxicity. Both the experts and external testers then completed an on-line exercise composed of two tasks: 1) rank cases in order of greatest to least GC-toxicity (experts' rankings were then compared to the ranking assigned by the weighted Composite GTI); and, 2) assign Composite GTI items to each case.

\author{
Statistical Analysis \\ Interrater reliability among raters and agreement between the experts' and external testers' \\ rankings and those of the Composite GTI were assessed using the Kappa statistic. The overall \\ interrater reliability of the ranking agreements was then calculated by averaging pairwise Kappa
}


values. All statistical analyses were performed on SAS Version 9.3 (SAS Institute, Cary, NC, USA).

\section{RESULTS}

Nine domains and 31 items were included in the Composite GTI (Table 1). Eleven domains and 23 items were included in the Specific List (Table 1)(See definitions, Appendices III and IV). Items reflect severity and account for impact of medications (e.g., blood pressure can be stable due to an increase in anti-hypertensive regimen). Toxicities such as atherosclerosis, myocardial infarction, and stroke were not included in the GTI because the SC agreed that all are confounded by co-morbid conditions (e.g., smoking) or disease effects (e.g., systemic lupus erythematosus). ${ }^{13}$ Except for bone mineral density, included because of its importance in GCrelated toxicity, ${ }^{14}$ items requiring imaging were excluded from the Composite GTI.

Fifteen experts participated in the weighting exercise at the face-to-face meeting. Seventeen of 19 experts and 17 independent raters completed this evaluation phase. The interrater reliability exercise revealed a high degree of agreement, with a kappa of $0.88(\mathrm{P}<0.01)$ for participating experts and kappa of $0.90(\mathrm{P}<0.01)$ for independent raters. The initial validity exercise revealed that both expert and independent rater case rankings had excellent agreement with rankings by the Composite GTI with a weighted kappa of $0.87(\mathrm{P}<0.01)$ and $0.77(\mathrm{P}<0.01)$, respectively.

\section{DISCUSSION}

A useful measurement of the steroid-sparing ability of new treatment agents requires a reliable outcomes-based instrument of GC-related toxicity. ${ }^{15,16}$ We describe a multi-specialty effort to 
develop the GTI, a comprehensive measure of change in GC-toxicity over time. The initial evaluation of the Composite GTI by participating experts and a multi-specialty group of external testers demonstrated excellent reliability and validity.

The development of two complementary assessment instruments within the GTI - the Composite GTI and the Specific List - was crucial in addressing several challenges in measuring GC toxicity. The creation of the Specific List permits documentation of certain important and often severe toxicities, leaving the Composite GTI as a relatively concise and easy to administer tool intended to detect differences between patients receiving divergent GC amounts. The inclusion of rare toxicities and those that may reflect prior GC use in the Specific List allowed us to simplify the usability, limit weight skewing, and minimize the effect of pre-trial GC therapy on the Composite GTI.

An important strength of the Composite GTI is the assignment of relative weights to each toxicity item in a systematic manner using MCDA. ${ }^{11}$ The MCDA approach greatly enhances the feasibility of this complex task in a way that group consensus methods struggle to approach. Further, the MCDA approach allows us to perform modifications of the Composite GTI as new data become available, including the addition and weighting of new items, without disrupting the validity of the method.

The next phase in GTI development includes the development of a web-based interface, prospective use in clinical trials, and input from patient support groups. Our initial evaluation exercise of the Composite GTI, including testing by an external group of glucocorticoid experts, 
implies excellent performance characteristics. The development of a web-based interface should further increase the instrument's reliability. For the GTI to be truly valid, it must be assessed in clinical trials and compared to doses of GCs administered, quality-of-life measures, and damage indices that include GC toxicity. ${ }^{17,18}$

In conclusion, we describe the development and initial evaluation of the GTI, a comprehensive GC toxicity assessment instrument. The GTI can be used across disciplines to assess the clinical value of steroid-sparing therapies, as well as to measure the impact of GC toxicity. Given the widespread use of GCs and the accelerating pace of immunological drug discovery, this instrument represents a considerable advance in our ability to assess the utility of new pharmacologic agents. 


\section{REFERENCES}

1. McDonough, A. K., Curtis, J. R. \& Saag, K. G. The epidemiology of glucocorticoidassociated adverse events. Curr. Opin. Rheumatol. 20, 131-7 (2008).

2. Sarnes E, Crofford L, Watson M, Dennis G, Kan H, B. D. Incidence and US costs of corticosteroid-associated adverse events: a systematic literature review. Clin Ther. 33, 1413-32 (2011).

3. Da Silva, J. A. P. et al. Safety of low dose glucocorticoid treatment in rheumatoid arthritis: published evidence and prospective trial data. Ann. Rheum. Dis. 65, 285-93 (2006).

4. Bel, E. H. et al. Oral glucocorticoid-sparing effect of mepolizumab in eosinophilic asthma. N. Engl. J. Med. 371, 1189-97 (2014).

5. Fortunet, C. et al. Tocilizumab induces corticosteroid sparing in rheumatoid arthritis patients in clinical practice. Rheumatology 54, 672-677 (2014).

6. van der Goes, M. C. et al. Monitoring adverse events of low-dose glucocorticoid therapy: EULAR recommendations for clinical trials and daily practice. Ann. Rheum. Dis. 69, 1913-9 (2010).

7. Rutgeerts, P. et al. A comparison of budesonide with prednisolone for active Crohn's disease. N. Engl. J. Med. 331, 842-5 (1994).

8. Capell, H. A. et al. Lack of radiological and clinical benefit over two years of low dose prednisolone for rheumatoid arthritis: results of a randomised controlled trial. Ann. Rheum. Dis. 63, 797-803 (2004).

9. Wassenberg, S., Rau, R., Steinfeld, P. \& Zeidler, H. Very low-dose prednisolone in early rheumatoid arthritis retards radiographic progression over two years: a multicenter, double-blind, placebo-controlled trial. Arthritis Rheum. 52, 3371-80 (2005).

10. Black, S. et al. Importance of background rates of disease in assessment of vaccine safety during mass immunisation with pandemic H1N1 influenza vaccines. Lancet (London, England) 374, 2115-22 (2009).

11. Johnson, S. R. et al. Multicriteria decision analysis methods with 1000Minds for developing systemic sclerosis classification criteria. J. Clin. Epidemiol. 67, 706-714 (2014).

12. Neogi, T. et al. 2015 Gout classification criteria: an American College of Rheumatology/European League Against Rheumatism collaborative initiative. Ann. Rheum. Dis. 74, 1789-1798 (2015).

13. Nikpour, M., Urowitz, M. B. \& Gladman, D. D. Epidemiology of atherosclerosis in systemic lupus erythematosus. Curr. Rheumatol. Rep. 11, 248-54 (2009).

14. Weinstein, R. S. Clinical practice. Glucocorticoid-induced bone disease. N. Engl. J. Med. 365, 62-70 (2011).

15. Bell, G. M., Reynolds, G. \& Isaacs, J. D. Biologic therapies in non-rheumatic diseases: lessons for rheumatologists? Nat. Rev. Rheumatol. 7, 507-16 (2011).

16. United States Food and Drug Administration. Guidance for Industry Systemic Lupus 
Erythematosus - Developing Medical Products for Treatment.

17. Ruiz-Arruza, I. et al. Glucocorticoids and irreversible damage in patients with systemic lupus erythematosus. Rheumatology (Oxford). 53, 1470-6 (2014).

18. Exley, A. R. et al. Development and initial validation of the Vasculitis Damage Index for the standardized clinical assessment of damage in the systemic vasculitides. Arthritis Rheum. 40, 371-80 (1997). 


\section{Figure Titles}

Figure 1 - GTI development milestones

6
7

8

9

10

11

12

13

14

15

16

17

18

19

20

21

22

23

24

25

26

27

28

29

30

31

32

33

34

35

36

37

38

39

40

41

42

43

44

45

46

47

48

49

50

51

52

53

54

55

56

57

58

59

60 


\begin{tabular}{|c|c|c|}
\hline Composite GTI & $\begin{array}{c}\text { Item } \\
\text { Weight }\end{array}$ & Specific List \\
\hline $\begin{array}{l}\text { Body mass index } \\
\text { Improvement in BMI } \\
\text { No change in BMI } \\
\text { Moderate increase in BMI } \\
\text { Major increase in BMI }\end{array}$ & $\begin{array}{c}-8 \\
0 \\
21 \\
36\end{array}$ & Major increase in BMI \\
\hline $\begin{array}{l}\text { Glucose tolerance } \\
\text { Improvement in glucose tolerance } \\
\text { No change in glucose tolerance } \\
\text { Worsening of glucose tolerance } \\
\text { Worsening of glucose tolerance despite } \\
\text { treatment }\end{array}$ & $\begin{array}{l}-8 \\
0 \\
32 \\
44\end{array}$ & $\begin{array}{l}\text { Diabetic retinopathy } \\
\text { Diabetic nephropathy } \\
\text { Diabetic neuropathy }\end{array}$ \\
\hline $\begin{array}{l}\text { Blood pressure } \\
\text { Improvement in blood pressure } \\
\text { No change in blood pressure } \\
\text { Worsening hypertension } \\
\text { Worsening hypertension despite treatment }\end{array}$ & $\begin{array}{c}0 \\
19 \\
44\end{array}$ & $\begin{array}{l}\text { Hypertensive emergency } \\
\text { Posterior reversible encephalopathy } \\
\text { syndrome }\end{array}$ \\
\hline $\begin{array}{l}\text { Lipids } \\
\text { Improvement in lipids } \\
\text { No change in lipids } \\
\text { Worsening hyperlipidemia } \\
\text { Worsening hyperlipidemia despite treatment }\end{array}$ & $\begin{array}{c}-9 \\
0 \\
10 \\
30\end{array}$ & \\
\hline $\begin{array}{l}\text { Bone density } \\
\text { Improvement in bone density } \\
\text { No change in bone density } \\
\text { Decrease in bone density }\end{array}$ & $\begin{array}{c}-1 \\
0 \\
29\end{array}$ & $\begin{array}{l}\text { Major decrease in bone density } \\
\text { Insufficiency fracture }\end{array}$ \\
\hline $\begin{array}{l}\text { Steroid myopathy } \\
\text { No steroid myopathy } \\
\text { Mild steroid myopathy } \\
\text { Moderate steroid myopathy or greater }\end{array}$ & $\begin{array}{l}0 \\
0 \\
9 \\
63\end{array}$ & Severe steroid myopathy \\
\hline $\begin{array}{l}\text { Skin toxicity } \\
\text { No skin toxicity } \\
\text { Mild skin toxicity } \\
\text { Moderate skin toxicity or greater }\end{array}$ & $\begin{array}{c}0 \\
8 \\
26\end{array}$ & Severe skin toxicity \\
\hline $\begin{array}{l}\text { Neuropsychiatric toxicity } \\
\text { No neuropsychiatric symptoms } \\
\text { Mild neuropsychiatric symptoms } \\
\text { Moderate neuropsychiatric symptoms or greater }\end{array}$ & $\begin{array}{c}0 \\
11 \\
74\end{array}$ & $\begin{array}{l}\text { Psychosis } \\
\text { GG-induced violence } \\
\text { Other severe neuropsychiatric symptoms }\end{array}$ \\
\hline $\begin{array}{l}\text { Infection } \\
\text { No significant infection } \\
\text { Oral/vaginal candidiasis or uncomplicated zoster } \\
\text { Grade } 3 \text { infection or greater }\end{array}$ & $\begin{array}{c}0 \\
19 \\
93\end{array}$ & $\begin{array}{l}\text { Grade } 4 \text { infection } \\
\text { Grade } 5 \text { infection }\end{array}$ \\
\hline Endocrine & & Adrenal insufficiency \\
\hline Gastrointestinal & & $\begin{array}{l}\text { Perforation } \\
\text { Peptic ulcer disease }\end{array}$ \\
\hline Musculoskeletal & & $\begin{array}{l}\text { Avascular necrosis } \\
\text { Tendon rupture }\end{array}$ \\
\hline Ocular & & $\begin{array}{l}\text { Central serous retinopathy } \\
\text { Intraocular pressure elevation } \\
\text { Posterior subcapsular cataract }\end{array}$ \\
\hline Total & -36 to 439 & \\
\hline
\end{tabular}




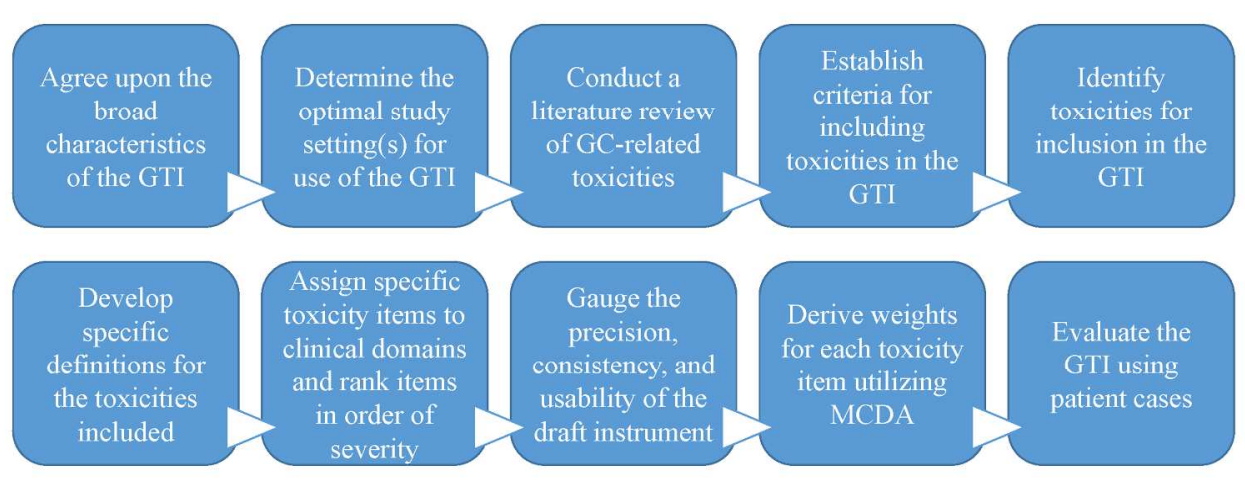

Process steps in the development of the Glucocorticoid Toxicity Index $327 \times 129 \mathrm{~mm}$ ( $300 \times 300$ DPI) 


\section{APPENDIX - Glucocorticoid toxicity references}

1. Smyllie HC, Connolly CK. Incidence of serious complications of corticosteroid therapy in respiratory disease. A retrospective survey of patients in the Brompton hospital. Thorax. 1968;23(6):571-581.

2. Fisher DE, Bickel WH. Corticosteroid-induced avascular necrosis. A clinical study of seventy-seven patients. J Bone Joint Surg Am. 1971;53(5):859-873.

3. Akingbehin AO. Corticosteroid-induced ocular hypertension. I. Prevalence in closedangle glaucoma. Br J Ophthalmol. 1982;66(8):536-540.

4. Messer J, Reitman D, Sacks HS, Smith H, Chalmers TC. Association of adrenocorticosteroid therapy and peptic-ulcer disease. N Engl J Med. 1983;309(1):21-24.

5. Bowyer SL, LaMothe MP, Hollister JR. Steroid myopathy: incidence and detection in a population with asthma. J Allergy Clin Immunol. 1985;76(2 Pt 1):234-242.

6. Felson DT, Anderson JJ. Across-study evaluation of association between steroid dose and bolus steroids and avascular necrosis of bone. Lancet (London, England). 1987;1(8538):902-906.

7. Delecoeuillerie G, Joly P, Cohen de Lara A, Paolaggi JB. Polymyalgia rheumatica and temporal arteritis: a retrospective analysis of prognostic features and different corticosteroid regimens (11 year survey of 210 patients). Ann Rheum Dis. 1988;47(9):733-739.

8. Patton PR, Pfaff WW. Aseptic bone necrosis after renal transplantation. Surgery. 1988;103(1):63-68.

9. Sooriyamoorthy M, Gower DB. Hormonal influences on gingival tissue: relationship to periodontal disease. J Clin Periodontol. 1989;16(4):201-208.

10. Vakil N, Sparberg M. Steroid-related osteonecrosis in inflammatory bowel disease. Gastroenterology. 1989;96(1):62-67.

11. Hricik DE, Mayes JT, Schulak JA. Independent effects of cyclosporine and prednisone on posttransplant hypercholesterolemia. Am J Kidney Dis. 1991;18(3):353-358.

12. Dropcho EJ, Soong SJ. Steroid-induced weakness in patients with primary brain tumors. Neurology. 1991;41(8):1235-1239.

13. Hawthorne AB, Record CO, Holdsworth CD, et al. Double blind trial of oral fluticasone propionate v prednisolone in the treatment of active ulcerative colitis. Gut. 1993;34(1):125-128.

14. Ong CS, Pollock CA, Caterson RJ, Mahony JF, Waugh DA, Ibels LS. Hyperlipidemia in renal transplant recipients: natural history and response to treatment. Medicine (Baltimore). 1994;73(4):215-223.

15. Leong KH, Koh ET, Feng PH, Boey ML. Lipid profiles in patients with systemic lupus erythematosus. J Rheumatol. 1994;21(7):1264-1267.

16. McDougall R, Sibley J, Haga M, Russell A. Outcome in patients with rheumatoid arthritis receiving prednisone compared to matched controls. J Rheumatol. 1994;21(7):1207-1213.

17. Saag KG, Koehnke R, Caldwell JR, et al. Low dose long-term corticosteroid therapy in rheumatoid arthritis: an analysis of serious adverse events. Am J Med. 1994;96(2):115123.

18. Conn HO, Poynard T. Corticosteroids and peptic ulcer: meta-analysis of adverse events during steroid therapy. J Intern Med. 1994;236(6):619-632.

19. Socié G, Sélimi F, Sedel L, et al. Avascular necrosis of bone after allogeneic bone 
marrow transplantation: clinical findings, incidence and risk factors. Br J Haematol. 1994;86(3):624-628.

20. Bradbury G, Benjamin J, Thompson J, Klees E, Copeland J. Avascular necrosis of bone after cardiac transplantation. Prevalence and relationship to administration and dosage of steroids. J Bone Joint Surg Am. 1994;76(9):1385-1388.

21. Fryer JP, Granger DK, Leventhal JR, Gillingham K, Najarian JS, Matas AJ. Steroidrelated complications in the cyclosporine era. Clin Transplant. 1994;8(3 Pt 1):224-229.

22. Stegall MD, Everson G, Schroter G, Bilir B, Karrer F, Kam I. Metabolic complications after liver transplantation. Diabetes, hypercholesterolemia, hypertension, and obesity. Transplantation. 1995;60(9):1057-1060.

23. Taler SJ, Textor SC, Canzanello VJ, et al. Role of steroid dose in hypertension early after liver transplantation with tacrolimus (FK506) and cyclosporine. Transplantation. 1996;62(11):1588-1592.

24. Jindal RM, Sidner RA, Hughes D, et al. Metabolic problems in recipients of liver transplants. Clin Transplant. 1996;10(2):213-217.

25. Keenan PA, Jacobson MW, Soleymani RM, Mayes MD, Stress ME, Yaldoo DT. The effect on memory of chronic prednisone treatment in patients with systemic disease. Neurology. 1996;47(6):1396-1402.

26. Naber D, Sand P, Heigl B. Psychopathological and neuropsychological effects of 8-days' corticosteroid treatment. A prospective study. Psychoneuroendocrinology. 1996;21(1):25-31.

27. Stegall MD, Everson GT, Schroter G, et al. Prednisone withdrawal late after adult liver transplantation reduces diabetes, hypertension, and hypercholesterolemia without causing graft loss. Hepatology. 1997;25(1):173-177.

28. Gabriel SE, Sunku J, Salvarani C, O'Fallon WM, Hunder GG. Adverse outcomes of antiinflammatory therapy among patients with polymyalgia rheumatica. Arthritis Rheum. 1997;40(10):1873-1878.

29. Akerkar GA, Peppercorn MA, Hamel MB, Parker RA. Corticosteroid-associated complications in elderly Crohn's disease patients. Am J Gastroenterol. 1997;92(3):461464.

30. Batchelor TT, Taylor LP, Thaler HT, Posner JB, DeAngelis LM. Steroid myopathy in cancer patients. Neurology. 1997;48(5):1234-1238.

31. Everhart JE, Lombardero M, Lake JR, Wiesner RH, Zetterman RK, Hoofnagle JH. Weight change and obesity after liver transplantation: incidence and risk factors. Liver Transpl Surg. 1998;4(4):285-296.

32. Augustine SM, Baumgartner WA, Kasper EK. Obesity and hypercholesterolemia following heart transplantation. J Transpl Coord. 1998;8(3):164-169.

33. Bar-Meir S, Chowers Y, Lavy A, et al. Budesonide versus prednisone in the treatment of active Crohn's disease. The Israeli Budesonide Study Group. Gastroenterology. 1998;115(4):835-840.

34. Zabinski SJ, Sculco TP, Dicarlo EF, Rivelis M. Osteonecrosis in the rheumatoid femoral head. J Rheumatol. 1998;25(9):1674-1680.

35. Lausten GS, Lemser T, Jensen PK, Egfjord M. Necrosis of the femoral head after kidney transplantation. Clin Transplant. 1998;12(6):572-574.

36. Henzen C, Suter A, Lerch E, Urbinelli R, Schorno XH, Briner VA. Suppression and recovery of adrenal response after short-term, high-dose glucocorticoid treatment. Lancet 
(London, England). 2000;355(9203):542-545.

37. Zonana-Nacach A, Barr SG, Magder LS, Petri M. Damage in systemic lupus erythematosus and its association with corticosteroids. Arthritis Rheum. 2000;43(8):18011808.

38. Formiga F, Meco JF, Pinto X, Jacob J, Moga I, Pujol R. Lipid and lipoprotein levels in premenopausal systemic lupus erythematosus patients. Lupus. 2001;10(5):359-363.

39. Karagas MR, Cushing GL, Greenberg ER, Mott LA, Spencer SK, Nierenberg DW. Nonmelanoma skin cancers and glucocorticoid therapy. Br J Cancer. 2001;85(5):683-686.

40. Hernández-Díaz S, Rodríguez LA. Steroids and risk of upper gastrointestinal complications. Am J Epidemiol. 2001;153(11):1089-1093.

41. Nielsen GL, Sørensen HT, Mellemkjoer L, et al. Risk of hospitalization resulting from upper gastrointestinal bleeding among patients taking corticosteroids: a register-based cohort study. Am J Med. 2001;111(7):541-545.

42. van Everdingen AA, Jacobs JWG, Siewertsz Van Reesema DR, Bijlsma JWJ. Low-dose prednisone therapy for patients with early active rheumatoid arthritis: clinical efficacy, disease-modifying properties, and side effects: a randomized, double-blind, placebocontrolled clinical trial. Ann Intern Med. 2002;136(1):1-12.

43. Brown ES, Suppes T, Khan DA, Carmody TJ. Mood changes during prednisone bursts in outpatients with asthma. J Clin Psychopharmacol. 2002;22(1):55-61.

44. Proven A, Gabriel SE, Orces C, O'Fallon WM, Hunder GG. Glucocorticoid therapy in giant cell arteritis: duration and adverse outcomes. Arthritis Rheum. 2003;49(5):703-708.

45. Gladman DD, Urowitz MB, Rahman P, Ibañez D, Tam L-S. Accrual of organ damage over time in patients with systemic lupus erythematosus. $J$ Rheumatol. 2003;30(9):19551959.

46. Van Staa TP, Laan RF, Barton IP, Cohen S, Reid DM, Cooper C. Bone density threshold and other predictors of vertebral fracture in patients receiving oral glucocorticoid therapy. Arthritis Rheum. 2003;48(11):3224-3229.

47. Kirwan JR, Hällgren R, Mielants H, et al. A randomised placebo controlled 12 week trial of budesonide and prednisolone in rheumatoid arthritis. Ann Rheum Dis. 2004;63(6):688695.

48. Bolanos SH, Khan DA, Hanczyc M, Bauer MS, Dhanani N, Brown ES. Assessment of mood states in patients receiving long-term corticosteroid therapy and in controls with patient-rated and clinician-rated scales. Ann Allergy Asthma Immunol. 2004;92(5):500505.

49. Steinbuch M, Youket TE, Cohen S. Oral glucocorticoid use is associated with an increased risk of fracture. Osteoporos Int. 2004;15(4):323-328.

50. Souverein PC, Berard A, Van Staa TP, et al. Use of oral glucocorticoids and risk of cardiovascular and cerebrovascular disease in a population based case-control study. Heart. 2004;90(8):859-865.

51. Wei L, MacDonald TM, Walker BR. Taking glucocorticoids by prescription is associated with subsequent cardiovascular disease. Ann Intern Med. 2004;141(10):764-770.

52. Svensson B, Boonen A, Albertsson K, van der Heijde D, Keller C, Hafström I. Low-dose prednisolone in addition to the initial disease-modifying antirheumatic drug in patients with early active rheumatoid arthritis reduces joint destruction and increases the remission rate: a two-year randomized trial. Arthritis Rheum. 2005;52(11):3360-3370.

53. Williams JJ, Lund LH, LaManca J, et al. Excessive weight gain in cardiac transplant 
recipients. J Heart Lung Transplant. 2006;25(1):36-41.

54. Curtis JR, Westfall AO, Allison J, et al. Population-based assessment of adverse events associated with long-term glucocorticoid use. Arthritis Rheum. 2006;55(3):420-426.

55. Da Silva JAP, Jacobs JWG, Kirwan JR, et al. Safety of low dose glucocorticoid treatment in rheumatoid arthritis: published evidence and prospective trial data. Ann Rheum Dis. 2006;65(3):285-293.

56. Jick SS, Lieberman ES, Rahman MU, Choi HK. Glucocorticoid use, other associated factors, and the risk of tuberculosis. Arthritis Rheum. 2006;55(1):19-26.

57. Maradit Kremers H, Reinalda MS, Crowson CS, Davis JM, Hunder GG, Gabriel SE. Glucocorticoids and cardiovascular and cerebrovascular events in polymyalgia rheumatica. Arthritis Rheum. 2007;57(2):279-286.

58. Fardet L, Flahault A, Kettaneh A, et al. Corticosteroid-induced clinical adverse events: frequency, risk factors and patient's opinion. Br J Dermatol. 2007;157(1):142-148.

59. Fardet L, Cabane J, Kettaneh A, Lebbé C, Flahault A. Corticosteroid-induced lipodystrophy is associated with features of the metabolic syndrome. Rheumatology (Oxford). 2007;46(7):1102-1106.

60. Bernatsky S, Hudson M, Suissa S. Anti-rheumatic drug use and risk of serious infections in rheumatoid arthritis. Rheumatology (Oxford). 2007;46(7):1157-1160.

61. Schneeweiss S, Setoguchi S, Weinblatt ME, et al. Anti-tumor necrosis factor alpha therapy and the risk of serious bacterial infections in elderly patients with rheumatoid arthritis. Arthritis Rheum. 2007;56(6):1754-1764.

62. Franklin J, Lunt M, Bunn D, Symmons D, Silman A. Risk and predictors of infection leading to hospitalisation in a large primary-care-derived cohort of patients with inflammatory polyarthritis. Ann Rheum Dis. 2007;66(3):308-312.

63. De Vries F, Bracke M, Leufkens HGM, Lammers J-WJ, Cooper C, Van Staa TP. Fracture risk with intermittent high-dose oral glucocorticoid therapy. Arthritis Rheum. 2007;56(1):208-214.

64. Varas-Lorenzo C, Rodriguez LAG, Maguire A, Castellsague J, Perez-Gutthann S. Use of oral corticosteroids and the risk of acute myocardial infarction. Atherosclerosis. 2007;192(2):376-383.

65. Davis JM, Maradit Kremers H, Crowson CS, et al. Glucocorticoids and cardiovascular events in rheumatoid arthritis: a population-based cohort study. Arthritis Rheum. 2007;56(3):820-830.

66. Wolfe F, Michaud K. The risk of myocardial infarction and pharmacologic and nonpharmacologic myocardial infarction predictors in rheumatoid arthritis: a cohort and nested case-control analysis. Arthritis Rheum. 2008;58(9):2612-2621.

67. Smitten AL, Choi HK, Hochberg MC, et al. The risk of hospitalized infection in patients with rheumatoid arthritis. J Rheumatol. 2008;35(3):387-393.

68. Lacaille D, Guh DP, Abrahamowicz M, Anis AH, Esdaile JM. Use of nonbiologic disease-modifying antirheumatic drugs and risk of infection in patients with rheumatoid arthritis. Arthritis Rheum. 2008;59(8):1074-1081.

69. Sosa M, Jódar E, Saavedra P, et al. Postmenopausal Canarian women receiving oral glucocorticoids have an increased prevalence of vertebral fractures and low values of bone mineral density measured by quantitative computer tomography and dual X-ray absorptiometry, without significant changes. Eur J Intern Med. 2008;19(1):51-56.

70. Panoulas VF, Douglas KMJ, Stavropoulos-Kalinoglou A, et al. Long-term exposure to 
medium-dose glucocorticoid therapy associates with hypertension in patients with rheumatoid arthritis. Rheumatology (Oxford). 2008;47(1):72-75.

71. Lieberman JR, Roth KM, Elsissy P, Dorey FJ, Kobashigawa JA. Symptomatic osteonecrosis of the hip and knee after cardiac transplantation. $J$ Arthroplasty. 2008;23(1):90-96.

72. Shibatani M, Fujioka M, Arai Y, et al. Degree of corticosteroid treatment within the first 2 months of renal transplantation has a strong influence on the incidence of osteonecrosis of the femoral head. Acta Orthop. 2008;79(5):631-636.

73. Thamer M, Hernán MA, Zhang Y, Cotter D, Petri M. Prednisone, lupus activity, and permanent organ damage. J Rheumatol. 2009;36(3):560-564.

74. Huscher D, Thiele K, Gromnica-Ihle E, et al. Dose-related patterns of glucocorticoidinduced side effects. Ann Rheum Dis. 2009;68(7):1119-1124.

75. Christiansen CF, Christensen S, Mehnert F, Cummings SR, Chapurlat RD, Sørensen HT. Glucocorticoid use and risk of atrial fibrillation or flutter: a population-based, casecontrol study. Arch Intern Med. 2009;169(18):1677-1683.

76. Campbell S, Sun C-L, Kurian S, et al. Predictors of avascular necrosis of bone in longterm survivors of hematopoietic cell transplantation. Cancer. 2009;115(18):4127-4135.

77. Greenberg JD, Reed G, Kremer JM, et al. Association of methotrexate and tumour necrosis factor antagonists with risk of infectious outcomes including opportunistic infections in the CORRONA registry. Ann Rheum Dis. 2010;69(2):380-386.

78. Strangfeld A, Eveslage M, Schneider M, et al. Treatment benefit or survival of the fittest: what drives the time-dependent decrease in serious infection rates under TNF inhibition and what does this imply for the individual patient? Ann Rheum Dis. 2011;70(11):19141920.

79. Grijalva CG, Chen L, Delzell E, et al. Initiation of tumor necrosis factor- $\alpha$ antagonists and the risk of hospitalization for infection in patients with autoimmune diseases. JAMA. 2011;306(21):2331-2339.

80. Durand M, Thomas SL. Incidence of infections in patients with giant cell arteritis: a cohort study. Arthritis Care Res (Hoboken). 2012;64(4):581-588.

81. Dixon WG, Abrahamowicz M, Beauchamp M-E, et al. Immediate and delayed impact of oral glucocorticoid therapy on risk of serious infection in older patients with rheumatoid arthritis: a nested case-control analysis. Ann Rheum Dis. 2012;71(7):1128-1133.

82. Fardet L, Petersen I, Nazareth I. Risk of cardiovascular events in people prescribed glucocorticoids with iatrogenic Cushing's syndrome: cohort study. BMJ. 2012;345:e4928.

83. Fardet L, Petersen I, Nazareth I. Suicidal behavior and severe neuropsychiatric disorders following glucocorticoid therapy in primary care. Am J Psychiatry. 2012;169(5):491-497.

84. Parker B, Urowitz MB, Gladman DD, et al. Clinical associations of the metabolic syndrome in systemic lupus erythematosus: data from an international inception cohort. Ann Rheum Dis. 2013;72(8):1308-1314.

85. Johannesdottir SA, Horváth-Puhó E, Dekkers OM, et al. Use of glucocorticoids and risk of venous thromboembolism: a nationwide population-based case-control study. JAMA Intern Med. 2013;173(9):743-752.

86. Sadr-Azodi O, Mattsson F, Bexlius TS, Lindblad M, Lagergren J, Ljung R. Association of oral glucocorticoid use with an increased risk of acute pancreatitis: a population-based nested case-control study. JAMA Intern Med. 2013;173(6):444-449. 
87. Fardet L, Nazareth I, Whitaker HJ, Petersen I. Severe neuropsychiatric outcomes following discontinuation of long-term glucocorticoid therapy: a cohort study. J Clin Psychiatry. 2013;74(4):e281-e286.

88. 100. del Rincón I, Battafarano DF, Restrepo JF, Erikson JM, Escalante A. Glucocorticoid dose thresholds associated with all-cause and cardiovascular mortality in rheumatoid arthritis. Arthritis Rheumatol (Hoboken, NJ). 2014;66(2):264-272.

89. Listing J, Kekow J, Manger B, et al. Mortality in rheumatoid arthritis: the impact of disease activity, treatment with glucocorticoids, TNFa inhibitors and rituximab. Ann Rheum Dis. 2015;74(2):415-421

90. Mont MA, Pivec R, Banerjee S, Issa K, Elmallah RK, Jones LC. High-Dose Corticosteroid Use and Risk of Hip Osteonecrosis: Meta-Analysis and Systematic Literature Review. J Arthroplasty. 2015;30(9):1506-1512.e5.

91. Lake KD, Reutzel TJ, Pritzker MR, Jorgensen CR, Emery RW. The impact of steroid withdrawal on the development of lipid abnormalities and obesity in heart transplant recipients. J Heart Lung Transplant. 12(4):580-590.

92. Taylor DO, Thompson JA, Hastillo A, et al. Hyperlipidemia after clinical heart transplantation. J Heart Transplant. 8(3):209-213; discussion 219-220.

93. Stuck AE, Minder CE, Frey FJ. Risk of infectious complications in patients taking glucocorticosteroids. Rev Infect Dis. 11(6):954-963.

94. Zazzali JL, Broder MS, Omachi TA, Chang E, Sun GH, Raimundo K. Risk of corticosteroid-related adverse events in asthma patients with high oral corticosteroid use. Allergy Asthma Proc. 36(4):268-274.

95. Renedo RJG, Sousa MM, Pérez SF, Zabalbeascoa JR, Carro LP. Avascular necrosis of the femoral head in patients with Hodgkin's disease. Hip Int. 20(4):473-481.

96. van der Goes MC, Jacobs JWG, Boers M, et al. Patient and rheumatologist perspectives on glucocorticoids: an exercise to improve the implementation of the European League Against Rheumatism (EULAR) recommendations on the management of systemic glucocorticoid therapy in rheumatic diseases. Ann Rheum Dis. 2010;69(6):1015-1021. 


\section{Appendix II - Multi-Criteria Decision Analysis Methods}

Multi-criteria decision analysis can be utilized to assign weights to items by ranking all possible combinations in order of severity of toxicity. 1000Minds software facilitates the process by determining the point values of multi-attribute value models and has been used in studies in healthcare, corporate management, agriculture, and environmental management. ${ }^{1}$ 1000Minds employs the "Potentially All Pairwise Rankings of all possible Alternatives" (PAPRIKA) method. ${ }^{2}$ PAPRIKA is based on the principle that an overall ranking of items in a model can be achieved if all possible pairwise combinations of the included items can be ranked. Ranking in a pairwise manner carries less cognitive burden then ranking multiple criteria simultaneously. Because the total number of pairwise rankings can number in the thousands, 1000Minds limits the number of pairwise rankings using the property of transitivity (if $\mathrm{A}>\mathrm{B}$ and $\mathrm{B}>\mathrm{C}$, then $\mathrm{A}>\mathrm{C}$ ). Any pairwise decision in which one option clearly has a higher weight (in this case, greater toxicity) based upon the outcomes of previous comparisons is not presented for consideration, thereby creating an efficiency of comparisons and permitting hundreds of comparisons within a few hours.

Participants were asked to assess the relative weight (toxicity) of items by selecting the higher toxicity from a paired patient scenario differing in two toxicity items. Figure 1 shows examples of the types of comparisons the Scientific Committee was made asked to make in deciding which combinations of clinical GC complications of GC use constituted the higher degree ofgreater GC toxicity. Using Turning Point voting technology (Youngstown, Ohio), experts anonymously chose the scenario with higher GC toxicity. The results of each vote were immediately presented to the full Scientific Committee and reasons for disagreement, if present, were discussed. If there was significant disagreement, the group re-voted after discussion of disagreements. This step was repeated if necessary. Consensus was achieved when all participants reached agreement or could accept the majority decision.

Based on the number of domains and toxicity items, there were 62,208 possible paired patient scenarios differing in two toxicity items. The participants completed 103 scenarios, reaching agreement on all combinations. The remaining 62,105 scenarios were then implicitly resolved using the transitivity principle within the 1000Minds software. Through iterative discrete pairwise choices, 1000Minds assigned relative weights to the items. 


\section{Figure 1}

\section{Which patient shows greater steroid-related toxicity?}

(given they're identical in all other respects)
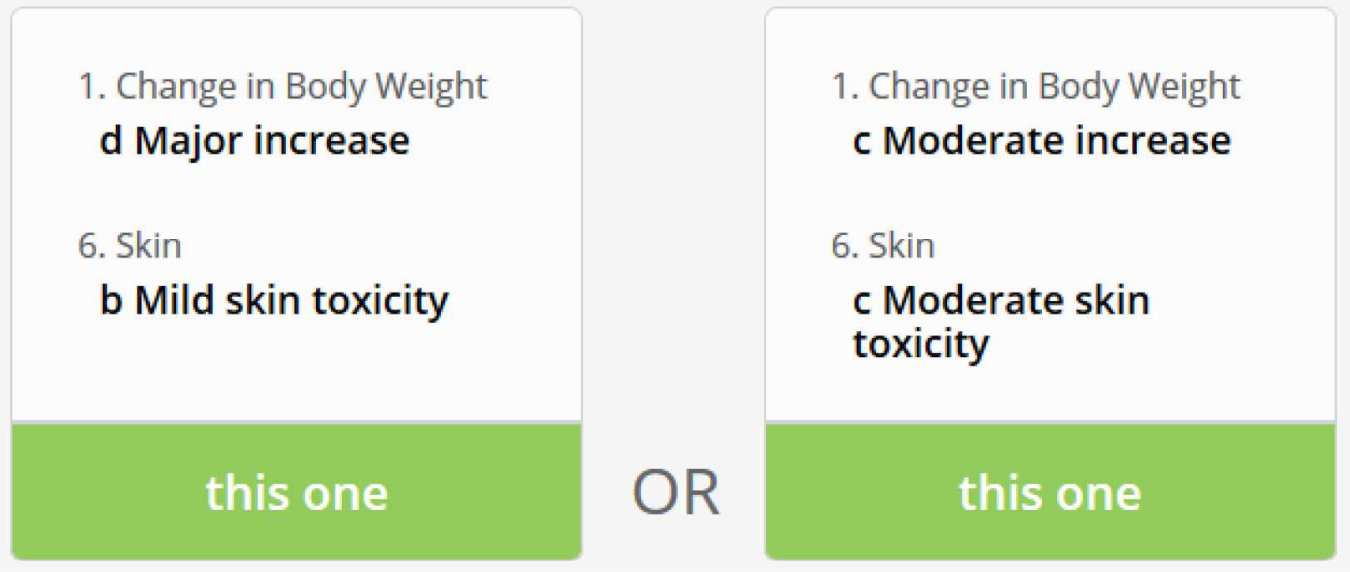

Screenshot from the exercise using 1000 Minds

\section{References}

1. 1000Minds homepage. https://www.1000minds.com. Accessed June 1, 2015.

2. Hansen P, Ombler F. A new method for scoring multi-attribute value models using pairwise rankings of alternatives. J Multi-Crit Decis Anal. 2009;15:87-107. 


\section{Appendix III - Composite Glucocorticoid Toxicity Index}

\section{Body Mass Index (BMI) (compared to baseline)}

a. Improvement in the direction of the normal range by more than 2 BMI units [normal range $=18.5-24.9 \mathrm{~kg} / \mathrm{m}^{2}$ ]

b. No significant change (BMI remains within +/-2 BMI units compared with baseline)

OR BMI remains within the normal range

c. Moderate increase in BMI (increase by more than 2 but less that 5 BMI units, to above the upper limit of normal BMI [24.9 kg/m $\left.\mathrm{m}^{2}\right]$ )

d. Major increase in BMI (increase by at least 5 but less than 8 BMI units above normal BMI $\left[24.9 \mathrm{~kg} / \mathrm{m}^{2}\right]$ )

\section{Glucose Tolerance (compared to baseline)}

a. Improvement in glucose tolerance:

- HbAlc declined $>10 \%$ from baseline without medication increase OR

- Decrease in diabetic medication without an increase in $\mathrm{HbA} 1 \mathrm{c}$ of $>10 \%$ or $\mathrm{HbA} 1 \mathrm{c}<5.7 \%$

b. No significant change in glucose tolerance:

- HbAlc within $10 \%$ of baseline or HbA1c $<5.7 \%$ AND no change in medication OR

- HbA1c increased to $>10 \%$ of baseline with a decrease in medication OR

- HbA1c decreased by $>10 \%$ of baseline with an increase in medication

c. Worsening of glucose tolerance or medication status:

- HbA1c $>5.7 \%$ and increased to $>10 \%$ of baseline without a change in medication OR

- Increase in diabetic medication with $<10 \%$ increase in $\mathrm{HbA} 1 \mathrm{c}$

d. Worsening of glucose tolerance despite increased treatment:

- $\mathrm{HbA} 1 \mathrm{c}>5.7 \%$ AND increased to $>10 \%$ of baseline AND an increase in diabetic medication

\section{Blood Pressure (BP) (compared to baseline)}

a. Improvement in BP:

- Decrease in BP of $>10 \%$ of baseline without medication increase, unless baseline systolic $\mathrm{BP} \leq 120$ and diastolic $\mathrm{BP} \leq 85$ OR

- Decrease in medication without an increase in $\mathrm{BP}$ of $>10 \%$, unless baseline systolic $\mathrm{BP} \leq 120$ and diastolic $\mathrm{BP} \leq 85$

b. No significant change in BP:

- BP within $10 \%$ of baseline or systolic $\mathrm{BP} \leq 120$ and diastolic $\mathrm{BP} \leq 85$ AND no change in medication OR

- Increase in either systolic or diastolic BP $>10 \%$ with a decrease in medication OR

- Improvement in systolic or diastolic BP of $>10 \%$ with an increase in medication c. Worsening of hypertension: 
4. Lipid metabolism (low-density lipoprotein [LDL] compared to baseline)

a. Improvement in lipids:

- Decrease in LDL concentration $>10 \%$ of baseline toward the target range without medication increase OR

- Decrease in medication without an increase in LDL of $>10 \%$ or LDL remains within target range

b. No significant change in LDL:

- LDL within $10 \%$ of baseline or within the target range for patient AND no change in medication OR

- Increase in LDL $>10 \%$ with a decrease in medication

OR

- Improvement in LDL of $>10 \%$ with an increase in medication

c. Worsening of LDL or medication status:

- Increase in LDL of $>10 \%$ to above target range without a change in medication OR

- Increase in medication with $<10 \%$ change in LDL

d. Worsening of LDL despite treatment:

- Increase in LDL of $>10 \%$ AND an increase in medication

\section{Bone Mineral Density (compared to baseline)}

a. Improvement - increase in BMD by $>3 \%$

b. No significant change (BMD between $-3 \%$ and $+3 \%$

c. Deterioration - decrease in BMD (BMD decrease by $->3 \%)$

$\%$ refers to total BMD in $\mathrm{gms} / \mathrm{cm}^{2}$

\section{Glucocorticoid-induced myopathy}

a. No steroid myopathy

b. Mild steroid myopathy (weakness WITHOUT functional limitation)

c. Moderate steroid myopathy (weakness WITH functional limitation)

\section{See Steroid Myopathy definitions, below}

\section{Skin}

a. No skin toxicity

b. Mild skin toxicity

c. Moderate skin toxicity 


\begin{tabular}{|l|}
\hline See Skin definitions, below \\
\hline 8. Neuropsychiatric toxicity \\
a. No neuropsychiatric symptoms \\
b. Mild neuropsychiatric symptoms \\
c. Moderate neuropsychiatric symptoms \\
See Neuropsychiatry definitions, below \\
9. Infection (since last assessment) \\
a. No significant infection \\
b. Specific infections < Grade 3 (oral or vaginal candidiasis, uncomplicated zoster) \\
c. Grade 3 or complicated herpes zoster \\
See Infection definitions, below
\end{tabular}




\section{Glucocorticoid-induced Myopathy Definitions}

Glucocorticoid-induced myopathy is defined as mild symmetrical weakness of the proximal muscles and/or neck flexors associated with steroid therapy, and NOT due to any other apparent cause. Muscle enzymes are typically within normal limits.

Mild and moderate severity of myopathy are defined by a muscle strength of 4 on the standard Medical Research Council rating scale.

A 4 means weaker than normal but greater than antigravity strength against resistance.

"Mild" is mild weakness (Grade 4) that does NOT functionally limit the patient.

"Moderate" is mild weakness (Grade 4) that does impose functional limitations on the patient enough to interfere with normal daily activities.

Note that a person may have muscle weakness consistent with glucocorticoid-induced myopathy that detectable on physical examination but might not be aware of it or have any corresponding functional limitation - this would be classified as mild.

Severe glucocorticoid-induced myopathy (defined as weakness of Grade 3 or less, which means no more than antigravity strength and unable to overcome any resistance or any degree weaker) is included in the Specific List. People who are severely weak may have difficulty rising from a chair without assistance or other major functional limitations but the formal categorization for severe should be based the degree of weakness on strength testing. 


\section{Severity of Glucocorticoid Toxicity in the Skin}

Manifestations to be considered:

- Acneiform rash

- Easy Bruising

- Hirsutism
- Atrophy/striae

- Erosions/tears/ulcerations

\begin{tabular}{|c|c|c|}
\hline $\begin{array}{l}\text { Skin 6b. Mild } \\
\end{array}$ & Skin 6c. Moderate & Severe (Specific Domain) \\
\hline Acneiform rash (Grades 1-2) & Acneiform rash (Grade 3) & Acneiform rash (Grade 4) \\
\hline Easy bruising (Grade 1) & Easy bruising (Grade 2) & \\
\hline Hirsutism (Grade 1) & Hirsutism (Grade 2) & \\
\hline Atrophy/Striae (Grade 1) & Atrophy/Striae (Grade 2) & Atrophy/Striae (Grade 3) \\
\hline Erosions/Tears/Ulcerations (Grade 1) & Erosions/Tears/Ulcerations (Grade 2) & Erosions/Tears/Ulcerations (Grade 3) \\
\hline
\end{tabular}

\section{Skin Definitions (from National Cancer Institute Common Terminology Criteria for Adverse Events):}

Gcneiform rash

- Grade 1 - Papules and/or pustules covering $<10 \%$ BSA, which may or may not be associated with symptoms of pruritus or tenderness

- Grade 2 - Papules and/or pustules covering 10 - 30\% BSA, which may or may not be associated with symptoms of pruritus or tenderness; OR associated with psychosocial impact; OR limiting instrumental ADL

- Grade 3 - Papules and/or pustules covering $>30 \%$ BSA, which may or may not be associated with symptoms of pruritus or tenderness; OR limiting self care ADL; OR associated with local superinfection with oral antibiotics indicated

- Grade 4 - Papules and/or pustules covering any \% BSA, which may or may not be associated with symptoms of pruritus or tenderness and are associated with extensive superinfection with IV antibiotics indicated; OR life- threatening consequences

y bruising

- Grade 1 - Localized or in a dependent area

- Grade 2 - Generalized

30Hirsutism - In women, increase in length, thickness or density of hair in a male distribution

31 - Grade 1 - Hirsutism that the patient is able to camouflage by periodic shaving, bleaching, or removal of hair

32 - Grade 2 - Hirsutism that requires daily shaving or consistent destructive means of hair removal to camouflage; OR associated with psychosocial impact 33Atrophy / Striae

34 - Grade 1 - Covering $<10 \%$ BSA; OR associated with telangiectasias or changes in skin color

35 - Grade 2 - Covering 10 - 30\% BSA; OR associated with striae or adnexal structure loss

- Grade 3 - Covering $>30 \%$ BSA; OR associated with ulceration

\section{Erosions / Tears / Ulcerations}

- Grade 1 - Combined area of ulcers $<1 \mathrm{~cm}$; OR nonblanchable erythema of intact skin associated with warmth or erythema

- Grade 2 - Combined area of ulcers $1-2 \mathrm{~cm}$; OR partial thickness skin loss involving skin or subcutaneous fat

- Grade 3 - Combined area of ulcers $>2 \mathrm{~cm}$; OR full-thickness skin loss involving damage to or necrosis of subcutaneous tissue that may extend down to fascia 


\section{Definitions of severity within the Neuropsychiatric Domain}

19Insomnia - Dissatisfaction with sleep quality and difficulty initiating or maintaining sleep or early morning awakening

20 - Grade 1: not associated with functional impairment

Grade 2: associated with functional impairment

\section{Manifestations to be considered:}

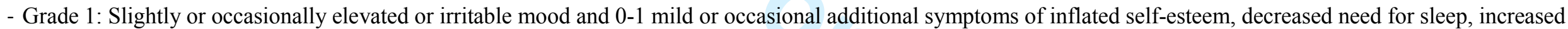
talkativeness, feeling that thoughts are faster than usual, distractibility, increased activity or agitation, and impulsive actions.

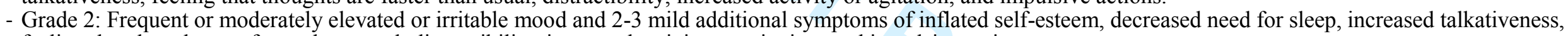
feeling that thoughts are faster than usual, distractibility, increased activity or agitation, and impulsive actions.

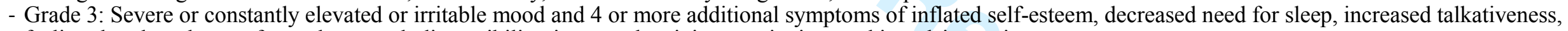
feeling that thoughts are faster than usual, distractibility, increased activity or agitation, and impulsive actions.

\section{Cognitive impairment}

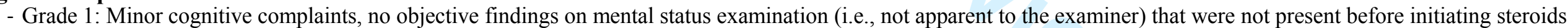

- Grade 2: New moderate cognitive deficits that were not present before initiating steroids

- Grade 3: Frank delirium

\section{Depression}

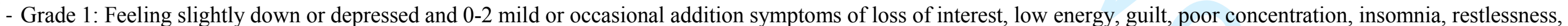
or change in appetite.

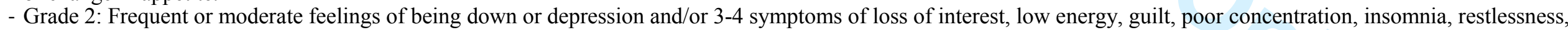
or change in appetite.

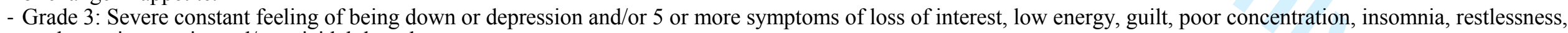
or change in appetite and/or suicidal thoughts. 


\section{Infection Definitions}

5

6 No significant infection $=$ No specific infections or serious infections, grade 3 or greater 7

8 Specific Infections - Oral or vaginal candidiasis or zoster infections without post-herpetic neuralgia or eye involvement 10

${ }_{11}$ Grade 3 - Intravenous antibiotic, antifungal, or antiviral intervention or hospitalization indicated OR radiologic or operative intervention 12indicated OR herpes zoster complicated by post-herpetic neuralgia or eye involvement 13

${ }_{15}^{14}$ Grade 4 or 5 - Life-threatening consequences; urgent intervention indicated OR death from infection (included in the Specific List) 16

\section{References}

20

${ }^{21}$ Medical Research Council of the United Kingdom. Guide to Examination of the Peripheral Nervous System: Memorandum No 45. Palo Alto, Calif: Pedragon House; 1978. 22

23 National Cancer Institute Common Terminology Criteria for Adverse Events v4.0 NCI, NIH, DHHS. May 29, 2009 NIH publication \# 09-7473. 


\section{Appendix IV - Specific List}

\begin{tabular}{|c|c|c|}
\hline$\sqrt[3]{30}$ & $\begin{array}{c}\text { At } \\
\text { Baseline } \\
\text { or Before }\end{array}$ & $\begin{array}{c}\text { New Since } \\
\text { Baseline }\end{array}$ \\
\hline $\begin{array}{l}\text { Body Mass Index } \\
-\quad \text { An absolute increase in BMI of more than } 8 \text { units (and }>24.9 \mathrm{~kg} / \mathrm{m}^{2} \text { ) }\end{array}$ & & \\
\hline $\begin{array}{l}\text { Blood Pressure } \\
-\quad \text { Hypertensive emergency (see definition, below) } \\
-\quad \text { PRES (Posterior reversible encephalopathy syndrome) (see definition, below) }\end{array}$ & & \\
\hline $\begin{array}{l}\text { Endocrine } \\
-\quad \text { Symptomatic adrenal insufficiency }\end{array}$ & & \\
\hline $\begin{array}{ll}\text { Bone Health } \\
- & \text { Osteonecrosis of one joint } \\
- & \text { Osteonecrosis of more than one joint } \\
- & \text { Bone mineral density decrease }>6 \% \\
- & \text { Insufficiency fracture } \\
- & \text { Insufficiency fracture in more than one bone }\end{array}$ & & \\
\hline $\begin{array}{l}\text { Muscle \& Tendon } \\
-\quad \text { Severe glucocorticoid myopathy (see definition) } \\
-\quad \text { Tendon rupture } \\
-\quad \text { More than one tendon rupture }\end{array}$ & & \\
\hline $\begin{array}{ll}\text { Eye } & \\
- & \text { Central serous retinopathy } \\
- & \text { New-onset or worsened elevation of intra-ocular pressure requiring treatment or change in treatment } \\
- & \text { Posterior subcapsular cataracts (or history of same) }\end{array}$ & 4 & \\
\hline
\end{tabular}




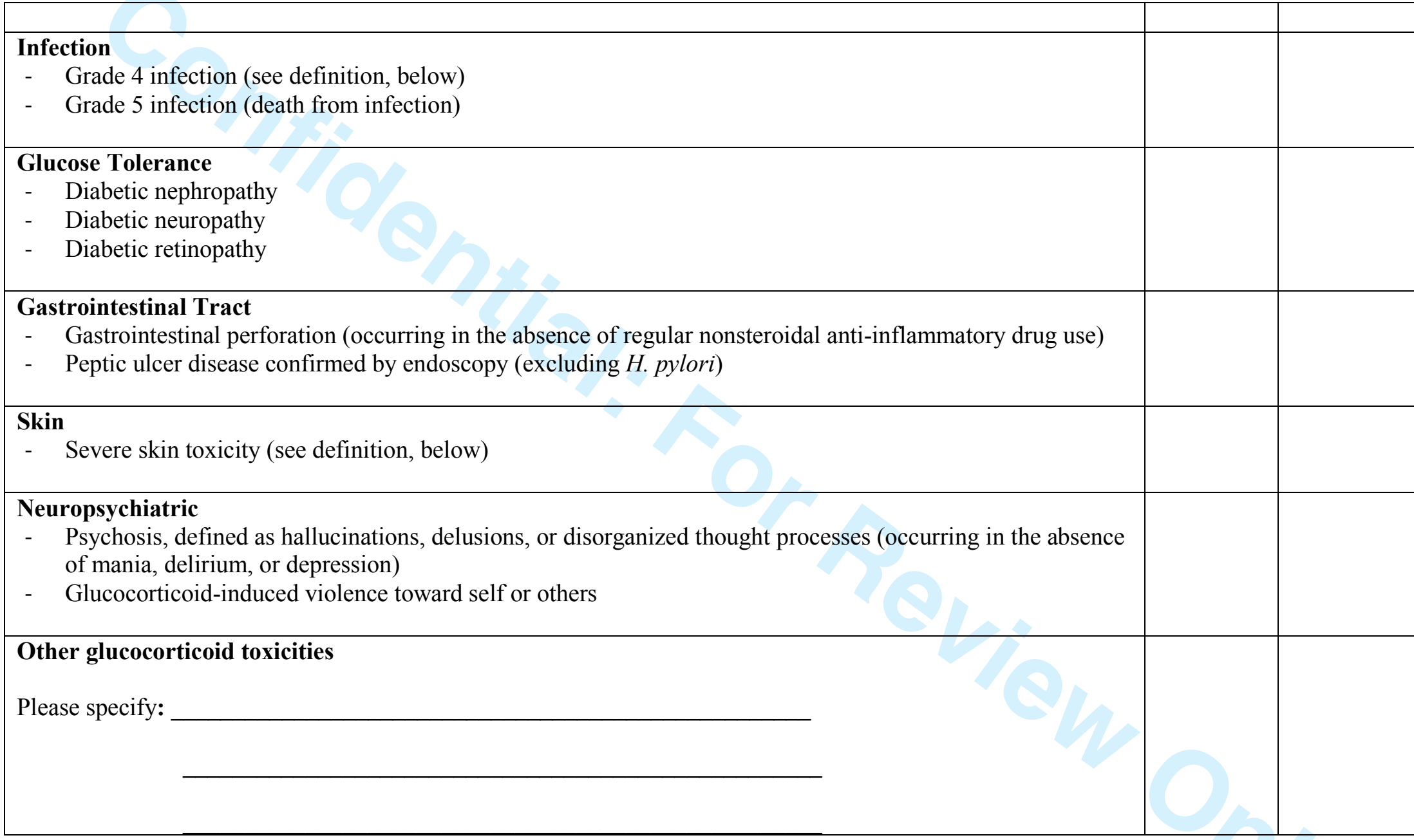




\section{DEFINITIONS:}

Hypertensive emergency: The blood pressure has reached levels that are damaging organs. Hypertensive emergencies generally occur at blood pressure levels exceeding $180 \mathrm{mmHg}$ systolic OR $120 \mathrm{mmHg}$ diastolic, but can occur at even lower levels in patients whose blood pressure have not been elevated before. Complications can include: stroke, loss of consciousness, memory loss, myocardial infarction, hypertensive retinopathy or nephropathy, aortic dissection, angina, pulmonary edema.

Posterior reversible leukoencephalopathy syndrome (PRES): A clinical radiological entity. Clinical features may include headaches, altered mental status, seizures, and visual loss, depending on the affected neuroanatomy. Characteristic Magnetic Resonance Imaging (MRI) findings include vasogenic edema involving the white matter that predominantly affects the posterior occipital and parietal lobes of the brain, although other brain regions may also be affected. Confirmation by MRI is required as is exclusion of other potential causes (including hypertensive emergency).

Severe glucocorticoid myopathy: Grade 3 or worse myopathic weakness or respiratory myopathic weakness attributable to glucocorticoid myopathy.

Central serous retinopathy: a fluid detachment of macula layers from their supporting tissue. Requires formal ophthalmology examination, typically accompanied by optical coherence tomography and/or fluorescein angiography for diagnostic confirmation.

Grade 4 infection: Life-threatening consequences (e.g., septic shock, hypotension, acidosis, necrosis).

Diabetic nephropathy: Macroalbuminuria; i.e., a urinary albumin excretion $>300 \mathrm{mg}$ in a 24-hour collection or a urinary protein: creatinine ratio $>300 \mathrm{mg} / \mathrm{g}$.

Diabetic neuropathy: Any of four types of peripheral neuropathy occurring in the setting of diabetes mellitus, namely: 1) a distal sensory polyneuropathy; 2) autonomic neuropathy (hypoglycemia unawareness, bladder or bowel problems, erectile dysfunction, and other autonomic nervous system issues); 3) diabetic amyotrophy (muscle infarction); or 4) mononeuritis (e.g., foot drop attributed to diabetic neuropathy). 
Diabetic retinopathy: Any form of retinopathy associated with diabetes mellitus, including both non-proliferative and proliferative forms of diabetic retinopathy as well as diabetic macular edema. These complications must be confirmed by an ophthalmologist.

Severe skin toxicity: Any of the three following manifestations:

Grade 4 acneiform lesions - Papules and/or pustules covering any \% body suraface area (BSA), which may or may not be associated with symptoms of pruritus or tenderness and are associated with extensive superinfection with IV antibiotics indicated or life- threatening consequences

Grade 3 striae - Covering $>30 \%$ BSA or associated with ulceration

Grade 3 ulcers - Combined area of ulcers $>2 \mathrm{~cm}$ or full-thickness skin loss involving damage to or necrosis of subcutaneous tissue that may extend down to fascia

\section{References}

National Cancer Institute Common Terminology Criteria for Adverse Events v4.0 NCI, NIH, DHHS. May 29, 2009 NIH publication \# 09-7473.

Medical Research Council of the United Kingdom. Guide to Examination of the Peripheral Nervous System: Memorandum No 45. Palo Alto, Calif: Pedragon House; 1978.

American Heart Association. Hypertensive Crisis. Accessed

http://www.heart.org/HEARTORG/Conditions/HighBloodPressure/AboutHighBloodPressure/Hypertensive-Crisis_UCM_301782_Article.jsp\#.V0NnSzv2ZaQ. $5 / 1 / 2015$. 
Supplementary Table 1. List of External Testers

\begin{tabular}{|l|l|l|}
\hline \multicolumn{1}{|c|}{ Tester } & \multicolumn{1}{c|}{ Specialty } & \multicolumn{1}{c|}{ Institution } \\
\hline Dr. George Stojan & Rheumatology & Beth Israel Deaconess Medical Center \\
\hline Dr. Kostantinos Tselios & Rheumatology & University of Toronto \\
\hline Dr. Charis Papadopoulou & Pediatric Rheum & Great Ormond Street Hospital \\
\hline Dr. Despina Eleftheriou & Pediatric Rheum & Great Ormond Street Hospital \\
\hline Dr. Lorcan McGarvey & Pulmonology & Queen's University, Belfast \\
\hline Dr. Julianna Desmarais & Rheumatology & Oregon Health Sciences University \\
\hline Dr. Sheenal Patel & lllergy/Immunology & University of Texas-Southwestern \\
\hline Dr. Zachary Wallace & Rheumatology & Massachusetts General Hospital \\
\hline Dr. Marlies van der Goes & Rheumatology & University of Utrecht \\
\hline Dr. Matthew Cascino & Rheumatology & University of California-San Francisco \\
\hline Dr. Stephen McAdoo & Nephrology & Hammersmith Hospital \\
\hline Dr. Sandra Hermann & Rheumatology & Charite Hospital \\
\hline Dr. Alexa Shipman & Dermatology & West Midlands Deanery, Birmingham, UK \\
\hline Dr. Cory Perugino & Rheumatology & Massachusetts General Hospital \\
\hline Dr. Matthew Tremblay & Neurology & University of California-San Fran \\
\hline Dr. Erin Wilfong & Rheumatology & University of California-San Francisco \\
\hline Dr. Mark Matsos & Rheumatology & McMaster University, Canada \\
\hline
\end{tabular}

